\title{
CIDADE DE NAMPULA: A RAINHA DO NORTE DE MOÇAMBIQUE
}

Manuel Mendes de AraúJo ${ }^{1}$

\author{
Ao Professor Doutor Carlos Alberto Medeiros, \\ pela sua incontornável contribuição \\ na formação de geógrafos dos países africanos \\ de língua oficial portuguesa (PALOPs).
}

\begin{abstract}
Resumo - A cidade de Nampula, localizada no interior norte de Moçambique, sempre foi considerada como a «capital do norte». Fundada com fins de controlo militar da penetração colonial para o interior, ela é um importante cruzamento de eixos de ligação entre o litoral e o interior e entre o centro e o extremo norte do país. Como as restantes áreas urbanas de Moçambique, a cidade de Nampula observou, no período pós-independência, um forte crescimento demográfico marcado, posteriormente pela guerra civil e, finalmente, pela paz que a partir de 1992 o país finalmente vive. Este crescimento foi resultado dum forte fluxo migratório vindo das áreas rurais. Como a cidade não viu crescer as suas infra-estruturas e a actividade económica, a ideia de vir para a cidade para melhorar as condições de vida da população migrante não passou duma miragem, o que resultou na proliferação da economia informal como forma de sobrevivência. A «cidade de cimento» continua a ter características urbanas e demográficas diferentes das dos postos administrativos urbanos circundantes.
\end{abstract}

Palavras-chave: População urbana, Moçambique, Nampula.

Abstract - The city of Nampula: Queen of northern Mozambique. The city of Nampula, located in the Northern hinterland of Mozambique, has always been considered the «capital of the North». Founded with the aim of ensuring military control over the colonial penetration of the hinterland, it is an important crossroads where the litoral-hinterland and centre-North axes intersect. Just like Mozambique's other urban areas, the city of Nampula underwent considerable demographic growth in the period that followed the independence of the country, including the period of civil war and the peace that ensued from 1992 onwards. This demographic growth was the result of a significant migration inflow originating in the rural areas.

1 Professor de Geografia Humana do Departamento de Geografia da Faculdade de Letras e Ciências Sociais da Universidade Eduardo Mondlane, e Director do Centro de Estudos de População da mesma Universidade, Maputo, Moçambique. E.mail: garmende@hotmail.com 


\begin{abstract}
As the city's infrastructure and economic activity was unable to keep apace with this growth, the idea of migrating to the city with the aim of improving the livelihood of the migrant population was nothing but a mirage, which eventually resulted in the proliferation of the informal economy as a means of livelihood. The «city of concrete» still exhibits a series of urban and demographic characteristics that differ substantially from those of the surrounding urban administrative units.
\end{abstract}

Key-words: Urban population, Mozambique, Nampula.

Résumé - La ville de Nampula, capitale du nord de Mozambique. La ville de Nampula, située dans l'intérieur nord du Mozambique, a toujours été considérée comme la 'capitale' du Nord. Fondée comme un poste de contrôle militaire de la pénétration coloniale, c'est un important carrefour de routes entre le littoral et l'intérieur, et entre le centre et le nord du pays. Comme les autres centres urbains du Mozambique, Nampula a connu, après l'Indépendance, un fort accroissement démographique, aussi bien pendant la guerre civile que depuis le rétablissement de la paix, en 1992. Cet accroissement résulte d'un important flux migratoire venu des campagnes. Mais Nampula n'ayant développé ni ses infrastructures ni son activité économique, le départ vers la ville n'a été qu'un mirage, qui explique la prolifération de l'économie informelle comme forme de survie des citadins. La 'ville de ciment' conserve des caractéristiques urbaines et démographiques qui l'individualisent par rapport aux postes administratifs urbains qui l'entourent.

Mots-clés: population urbaine, Mozambique, Nampula.

\title{
I. CRUZAMENTO DE CAMINHOS
}

Localizada no entroncamento da via férrea de Nacala com os eixos rodoviários que da província da Zambézia e do litoral demandam o norte e o interior, a cidade de Nampula foi implantada num planalto, para servir de centro militar colonial para todo o norte de Moçambique. Ela é atravessada pelo «corredor de desenvolvimento de Nacala», constituído pelos eixos ferroviário e rodoviário que ligam o litoral (porto de Nacala) com o interior do país e com a República do Malawi. Também é cruzada pelo eixo rodoviário Centro-Nordeste, vital para o desenvolvimento a norte do rio Zambeze e que, a partir daqui, se ramifica em direcção à província de Cabo Delgado, a norte, a província do Niassa, a ocidente, e o litoral, a oriente. É esta localização que lhe confere o papel de centro económico e de ligação de todo o território a norte do rio Zambeze, pelo que se lhe ajusta o título de "capital nortenha» ou «rainha do norte».

A cidade de Nampula situa-se, aproximadamente, no centro do espaço geográfico do distrito que leva o mesmo nome (distrito de Nampula), um pouco deslocada para NE, e ocupa uma área de $404 \mathrm{~km} 2$. De Este para Oeste tem uma extensão de $24,5 \mathrm{~km}$, entre os meridianos de $39 .^{\circ} 23^{\prime} 28^{\prime}$ e $39 .^{\circ} 10^{\prime} 00^{\prime}$ Este. No sentido N-S estende-se por $20,25 \mathrm{~km}$, desde a barragem do rio Monapo, a uma latitude de $15 .^{\circ} 01$ » $35^{\prime} \mathrm{S}$, até ao riacho Muepelume, no paralelo 15. ${ }^{\circ} 13^{\prime} 15^{\prime} \mathrm{S}$.

Administrativamente, a cidade constitui um município, mas que não per- 
tence ao distrito rural de Nampula que, territorialmente a cerca. Como «ilha» dentro do distrito, toda a expansão da cidade se faz à custa do território daquela entidade administrativamente diferente. Isto tem colocado alguns problemas, pois a cidade vai retirando do distrito rural territórios que serviam para o desenvolvimento social e económico deste, assim como lhe subtrai impostos de actores económicos que, por alteração de limites administrativos, passam a ser pagos à cidade. Assim, a cidade, por natureza um espaço dominante, torna-se mais hegemónico e centralizador. Foi isto que ocorreu em 1986 quando, de forma administrativa e burocrática, foram aumentados os limites territoriais das áreas urbanas em Moçambique.

\section{BREVES NOTAS SOBRE A HISTÓRIA DA CIDADE}

A primeira penetração portuguesa no interior do território da actual província de Nampula remonta a 1896, com o objectivo de ocupar e colonizar os reinos de Macuana, Maurusa e Mongole. Nesta primeira investida colonial para terras do interior foram fundados, em 1897, os postos de Ibraímo, Nameluco e Itaculo, a pouco mais de meia centena de quilómetros do litoral. Este último passou a funcionar como sede de capitania.

A 7 de Fevereiro de 1907, uma expedição da armada portuguesa acampou na senzala do régulo Uampula (Nampula) (Conselho Executivo Da Cidade De Nampula, 1992), tendo aqui construído um posto militar. Nesta altura a sede da capitania foi transferida de Itoculo para Nampula, passando a funcionar como centro da expansão portuguesa em todo o norte de Moçambique.

Entre 1907 e 1913, a partir do posto militar de Nampula, foram subjugados cerca de 44 régulos. Também foi neste período que, em 1912, se iniciou a construção da linha-férrea a partir da vila do Lumbo, no litoral em frente à Ilha de Moçambique. Contudo, só após a 1. ${ }^{\mathrm{a}}$ Guerra Mundial esta avançou para o interior.

A 21 de Julho de 1917 foram extintas as 4 capitanias então existentes e, em seu lugar, criaram-se 15 comandos militares, um dos quais foi o de Macuana, com sede no povoado de Nampula. Esta estratégia foi imposta pela forte resistência que os regulados opunham à penetração colonial.

A 6 de Dezembro de 1919 foi criada, na localidade de Nampula, pertencente ao comando militar de Macuana, a primeira delegação da Fazenda com o objectivo de recolher os impostos ('mucossa') que já haviam sido lançados no período de 1907-1913.

Em 1921 o governo português considerou ter chegado ao fim a missão dos comandos militares nas suas colónias. Por isso, a 30 de Junho de 1921 estes foram extintos em Moçambique, tendo sido substituídos por circunscrições civis. A 8. ${ }^{a}$ circunscrição manteve o nome de Macuana, com sede na localidade de Nampula e incluía, igualmente, o posto administrativo de Murrupula.

Em 1930 a linha-férrea, iniciada 28 anos antes (1912) no Lumbo, chega 
finalmente à localidade de Nampula, o que leva a que a administração colonial, para esta região da colónia, se fixe aqui de forma definitiva. Cerca de 4 anos depois, a 19 de Dezembro de 1934, esta localidade é elevada à categoria de vila, o que vem reforçar a importância estratégica, política e económica que sempre lhe foi atribuída. Um ano depois (1935), a vila de Nampula passa a ser a capital do «território do Niassa», que abrangia os espaços geográficos das actuais províncias de Nampula, Cabo Delgado e Niassa; isto é, era a partir da vila de Nampula que o regime colonial governava todo o extenso território a norte do rio Ligonha, correspondente a uma superfície de $275.042 \mathrm{~km} 2$. Nesta altura, devido à sua importância e ao extenso território que administrava, instala-se na vila de Nampula o primeiro governador, que é acompanhado pela criação dos serviços de administração civil, de obras públicas, de agricultura, de agrimensura, de indústria e geologia, de saúde, de instrução, de veterinária, dos correios e telégrafos.

No dia 4 de Setembro de 1940 é criada a diocese de Nampula, dando-se início a uma intensa ocupação missionária. É nesta altura que o ensino secundário observa o seu primeiro grande impulso com a abertura dos 2 primeiros colégios/liceus e uma escola técnica elementar. Também é na década de 40 que se cria a comarca de Nampula, facto que corta toda a dependência administrativa desta com a Ilha de Moçambique.

Em 26 de Agosto de 1956, a vila de Nampula é elevada à categoria de cidade, com a denominação de "Cidade de Nampula».

Durante a guerra colonial, a cidade de Nampula funcionou como o centro nevrálgico de todas as operações militares do exército português, tendo, durante esse período, que decorreu de 1964 a 1974, criado grandes infraestruturas militares. Por isso, actualmente ali funciona a Academia Militar de Moçambique.

\section{DIVISÃO ADMINISTRATIVA}

A urbe de Nampula constitui um município e, administrativamente, tem equivalência a um distrito. É formada por 6 postos administrativos urbanos que englobam 18 bairros, conforme o quadro I.

O município é dirigido pela Assembleia Municipal e pelo Presidente do Conselho Municipal, eleitos por voto directo dos munícipes. No entanto, os chefes dos postos administrativos urbanos são nomeados pelo governador da província, o que cria um enviezamento do poder local autárquico e, por vezes, dificuldades de gestão e administração urbanas. 
Quadro I - Divisão administrativa da cidade de Nampula

Table I-Administrative organisation of the city of Nampula

\begin{tabular}{ll}
\hline \multicolumn{1}{c}{ Postos administrativos urbanos } & \multicolumn{1}{c}{ Bairros } \\
\hline Central & Bombeiros; 25 de Setembro; 1... de Maio; Limoeiros; \\
& Liberdade; Militar \\
Muatala & Muatala; Mutauhanha \\
Muhala & Muhala; Namutaqueliua; Muahivire \\
Namicopo & Namicopo; Mutava-Rex \\
Napipine & Napipine; Carrupeia \\
Natikiri & Natikiri; Marrupaniua; Marrere \\
\hline
\end{tabular}

O posto administrativo urbano Central, como o próprio nome indica, constitui o centro geográfico, económico, administrativo e urbano da cidade, e corresponde à «cidade de cimento», planeada, de desenvolvimento vertical, onde se situam as principais infra-estruturas económicas, sociais e administrativas; a antiga cidade colonial, habitada, exclusivamente, por população branca e alguma mulata e assimilada. Corresponde a um modelo urbano tipicamente «ocidental», de planta ortogonal, estruturado em amplas avenidas, com áreas residenciais e de serviços bem demarcadas.

Os outros 5 postos administrativos cercam, por completo, o anterior, e constituem a «cidade de caniço», actualmente em plena transformação e expansão. Os bairros destes postos administrativos, eram os bairros segregados de população negra que se aproximava da «cidade de cimento» à procura de trabalho, assim como áreas rurais, habitadas por camponeses que, pela reforma administrativa de 1986 ficaram integradas dentro dos novos limites da cidade. É nestes que ainda hoje se instala a população migrante e com menos recursos económicos; o planeamento é incipiente ou inexistente, predomina a ocupação espontânea e anárquica, o desenvolvimento é horizontal e são escassas ou inexistentes as infra-estruturas urbanas. Continuam a ser espaços segregados, apesar das transformações que têm ocorrido nos últimos anos.

O posto administrativo urbano de Namicopo ocupa todo o NE da cidade; é por este que entra na cidade o eixo rodoviário e ferroviário que vem do porto de Nacala. O posto administrativo urbano de Napipine localiza-se a $\mathrm{N}$, e é nele que fica a barragm que abastece de água a cidade. O ocidente é ocupado pelo posto administrativo urbano de Natikiri; ele é atravessado pelo eixo ferro-rodoviário que se dirige para a província do Niassa e a República do Malawi. O sul da cidade é ocupado pelos postos administrativos urbanos de Muatala, a ocidente, e de Muhala, onde se localizam os dois bairros mais populares e conhecidos da cidade - Muahivire e Namutaqueliua, desde o tempo colonial ligados aos nomes do Benfica e do Sporting, respectivamente. 


\section{UMA POPULAÇÃO EM CRESCIMENTO MUITO RÁPIDO}

Os espaços urbanos em Moçambique conheceram, logo após a independência nacional, um aumento demográfico muito acentuado, como resultado da «tomada» das cidades pela população moçambicana. Este elevado ritmo de crescimento manteve-se nos anos seguintes devido ao grande número de pessoas que abandonavam as áreas rurais devido à instabilidade política provocada pela guerra civil terminada em 1992 (ARAÚJO, 2000).

Em 1970, cinco anos antes da independência nacional, a cidade de Nampula tinha uma população de apenas 23.072 residentes, o que não chegava a representar $1 \%$ da população provincial. No ano de 1980, cinco anos após o país se ter libertado do regime colonial, nesta urbe viviam 145.722 habitantes, o que correspondia a 6,5\% da população de toda a província de Nampula, e a uma taxa de crescimento médio anual de 20,2\% (CONSElHo CoORDENADOR Do RECENSEAMENTO, 1982). Em 1991, de acordo com a enumeração realizada pela Direcção Nacional de Estatística, os residentes nesta cidade eram 232.167; neste período (1980-1991) a taxa média anual de crescimento demográfico foi de 4,3\% (Direcção Nacional de Estatística, 1992). O II Recenseamento Geral da População e Habitação, realizado em 1997, indica uma população residente de 303.346 habitantes (InSTituto NaCional DE Estatística, 1999), que representa $10,2 \%$ da população provincial; neste último período (1991-1997) a taxa média anual de crescimento foi ligeiramente superior ao anterior, situando-se nos $4,5 \%$. Isto significa que no período entre os dois recenseamentos (1980-1997) o peso da população da cidade de Nampula no total da população da província onde se insere, aumentou substancialmente (mais 3,7\%), como resultado da forte migração rural urbana que se observou em todo o país. Em 27 anos (19701997) a urbe nampulense sextuplicou a sua população (Figura 1).

Ao contrário do que seria de esperar e das expectativas dos políticos e gestores, a cidade de Nampula viu aumentar mais a sua população no pós-guerra civil (a partir de 1991) do que no período anterior. Isto sucede pelo facto de as áreas rurais da província terem sido muito devastadas e se tornarem muito repulsivas; nessas condições, os que haviam migrado para a cidade para fugir à guerra, não regressaram às suas áreas de origem, e o campo continuou a expulsar pessoas, pois não lhes oferecia condições mínimas de sobrevivência.

Entre 1980 a 1991, a taxa de crescimento médio anual foi de 4,3\%, passando para 4,5\% no período seguinte (1991-97) (ARAúJo, 2003). Estes dados são reveladores de que a população que durante a guerra civil procurou a cidade como refúgio, não retornou aos seus locais de origem e, pelo contrário, a procura dos espaços urbanos cresceu um pouco mais devido, fundamentalmente, às más condições de vida e situação económica das áreas rurais. $\mathrm{O}$ aumento do crescimento populacional urbano no período pós-guerra civil não se observou na maior parte das cidades moçambicanas; a cidade de Nampula faz parte dum pequeno conjunto de centros urbanos que observou um maior crescimento neste período, e que coincidem com as que menos aumentaram durante o período anterior (ARAÚJo, 2003). 


\section{População x $\mathbf{1 0}^{3}$}

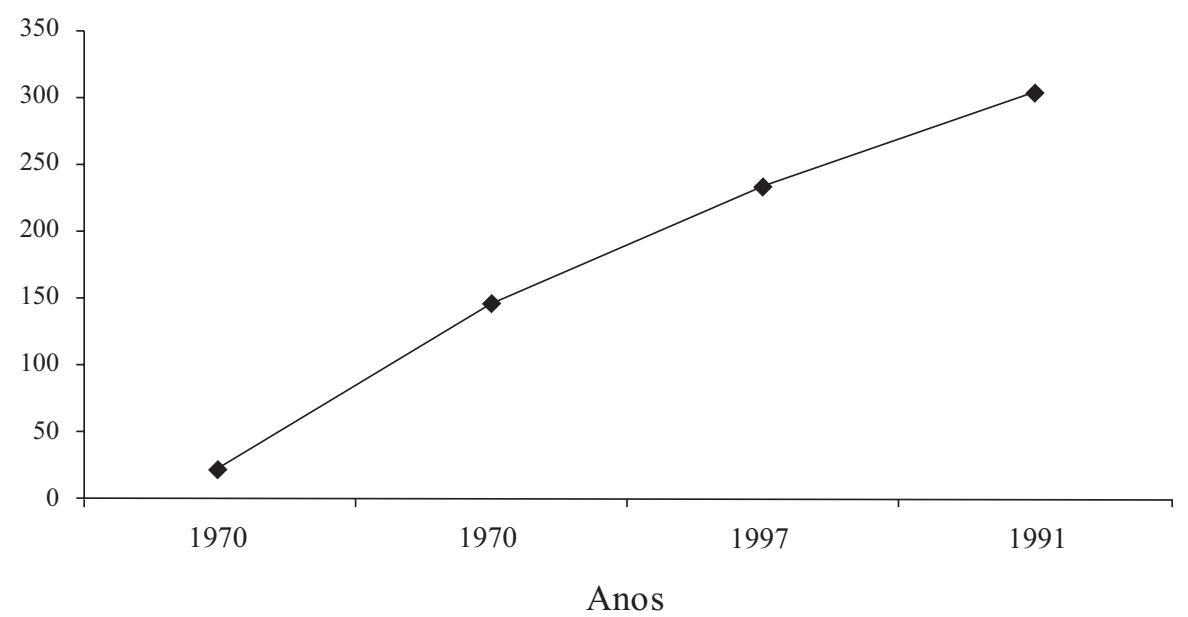

Fig. 1. Crescimento da população da cidade de Nampula (1970-1997)

Fig. 1 - Population growth in Namula (1970-1997)

De acordo com as projecções mais recentes do INE, entre 1997 e 2005 o ritmo do crescimento da população da cidade de Nampula não passará dos 3,0\% (quadro II). Mas de acordo com o Conselho Municipal da cidade, entre 97 e 2002, o crescimento demográfico manteve-se na ordem dos $4 \%$ ao ano, prevendo que a população em 2005 se aproxime dos 400 mil habitantes.

O aumento demográfico observado entre 1980 e 1997 levou a uma duplicação da densidade demográfica urbana (quadro II), em particular nos bairros mais pobres.

Quadro II - Evolução da população da cidade de Nampula (1980-2005)

Table II - Population change in Nampula (1980-2005)

\begin{tabular}{lcccc}
\hline & 1980 & 1991 & 1997 & \multicolumn{2}{c}{$2005^{*}$} \\
\hline População & 145.722 & 232.167 & 303.346 & 385.089 \\
Taxa de crescimento médio anual & $4,3 \%$ & \multicolumn{2}{c}{$4,5 \%$} & \\
Densidade & 361 & 575 & 751 & $3,0 \%$ \\
\hline
\end{tabular}

*Projecção elaborada pelo Instituto Nacional de Estatística (INE). 


\section{DISTRIBUIÇÃO TERRITORIAL DA POPULAÇÃO DA CIDADE DE NAMPULA}

Considerando as unidades territoriais administrativas intra-urbanas, os postos administrativos, o aumento da população foi bastante diferente, conforme ilustram o quadro III e a figura 2. A «cidade de cimento» (posto administrativo Central) e o posto administrativo de Natikiri, no extremo ocidental da área urbanizada, foram os que menos cresceram ao longo do período aqui considerado (1980-1997).

Em Natikiri, em 1980 residia 20,4\% da população da cidade, mas 17 anos depois (1997) a população aqui residente representava, apenas, 10,8\% dos moradores de toda a cidade. Num período de 17 anos este posto administrativo teve apenas um aumento absoluto de 3 mil habitantes, ao contrário de Napipine, por exemplo, que viu os seus moradores acrescidos de mais 42.000 . A situação naquele posto administrativo urbano foi resultado das condições de insegurança, provocadas pela guerra civil, pois esta área estava muito próxima de territórios rurais onde as acções dos rebeldes se faziam sentir com muita frequência contra a população. Além disso, é uma área urbana muito periférica com poucas ou nenhumas infra-estruturas urbanas e sócio-económicas. Por isso, não sendo atractiva, muita da sua população migrava para as áreas urbanas vizinhas, com melhores condições de vida, como Napipine, a NE e Muatala a SE.

Quadro III - Distribuição da população da cidade de Nampula por postos administrativos urbanos (1980-1997)

Table III-Distribution of the population of the city of Nampula by urban administrative units

\begin{tabular}{|c|c|c|c|c|c|c|c|}
\hline & \multicolumn{2}{|c|}{1980} & \multicolumn{2}{|c|}{1991} & \multicolumn{2}{|c|}{1997} & \multirow{2}{*}{$\begin{array}{c}\text { Aumento (\%) } \\
1980=100 \\
\end{array}$} \\
\hline & Pop. & $\%$ & Pop. & $\%$ & Pop. & $\%$ & \\
\hline Central & 10.992 & 7,5 & 14.458 & 6,2 & 16.229 & 5,3 & 147,6 ( 1,5 vezes) \\
\hline Muatala & 29.707 & 20,4 & 57.168 & 24,6 & 72.425 & 23,9 & 243,2 ( 2,4 vezes) \\
\hline Muhala & 32.394 & 22,2 & 54.485 & 23,5 & 80.006 & 26,4 & 247,0 (2,5 vezes) \\
\hline Namicopo & 16.468 & 11,3 & 14.463 & 6,2 & 33.557 & 11,1 & 203,8 ( 2,0 vezes) \\
\hline Napipine & 26.436 & 18,2 & 57.386 & 24,7 & 68.410 & 22,5 & 258,8 ( 2,6 vezes) \\
\hline Natikiri & 29.725 & 20,4 & 34.207 & 14,8 & 32.719 & 10,8 & $110,1$ ( 1,1 vezes $)$ \\
\hline Total & 145.722 & 100 & 232.167 & 100 & 303.346 & 100 & $208,2$ ( 2,1 vezes $)$ \\
\hline
\end{tabular}

Fonte: Conselho Coordenador do Recenseamento, 1. ${ }^{\circ}$ Recenseamento Geral da População, 1980. Serviços Provinciais de Estatística, Direcção Provincial do Plano, Nampula, 1992. Instituto Nacional de Estatística, II Recenseamento Geral da População e Habitação, 1997.

O posto administrativo Central ('cidade de cimento'), durante este período de 17 anos apenas aumentou a sua população em 5 mil pessoas, constituindo, 
com o de Natikiri, os únicos bairros que perderam peso demográfico no conjunto da cidade. Mas aqui, as razões são completamente diferentes das que actuaram em Natikiri; a "cidade de cimento" continua, como no passado, a ser muito selectiva, apenas aceitando população com poder económico e de estatuto social considerado como mais elevado. Além disso, o tipo de residências permitidas neste espaço urbano, assim como o material de construção, limita o seu acesso a uma grande maioria da população moçambicana. Mas mesmo assim o centro da cidade de Nampula está congestionado. Isto sucede porque durante o período em análise não houve novas construções para habitação. A isto acresce o facto de que, durante o dia, um grande número de moradores dos outros postos administrativos urbanos vem trabalhar e/ou fazer a sua actividade de comércio de rua (informal) no centro, onde existe poder de compra. Esta situação cria, para os residentes, a percepção de um grande congestionamento populacional.

O posto administrativo de Namicopo, apesar de ter duplicado a sua população no período em análise, manteve o mesmo peso no conjunto da cidade.

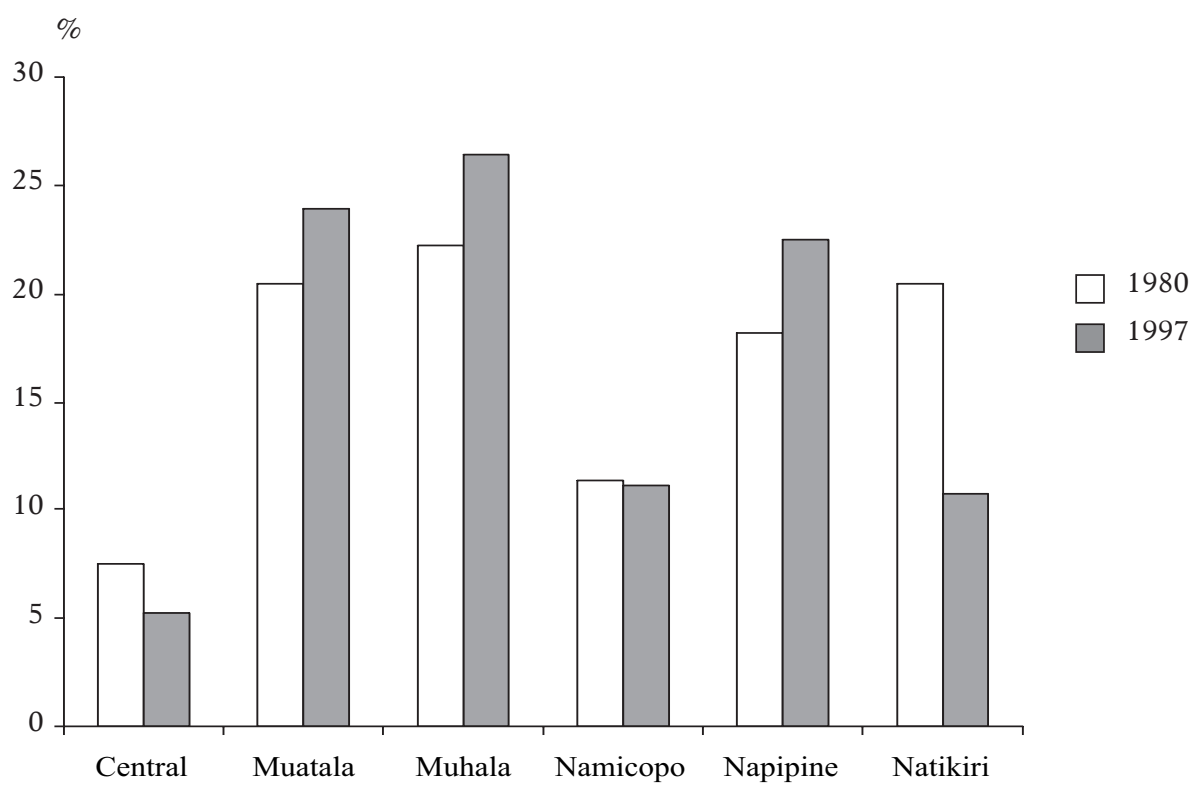

Fig. 2 - Evolução do peso da população dos postos administrativos em Nampula

Fig. 2-Change in the weight of the population in the administrative organisation of Nampula

Os principais responsáveis pelo grande crescimento demográfico da cidade de Nampula foram os postos administrativos designados por suburbanos, com excepção do de Natikiri, particularmente os de Muatala, Muhala e Napipine 
(quadro III e fig. 2). São espaços suburbanos constituídos por bairros populares tradicionais, de crescimento horizontal, onde o material de construção predominante é precário (material local). Nestas condições, o crescimento demográfico observado levou a uma ocupação muito densa do solo, sem qualquer ordenamento e sem criação de infra-estruturas urbanas. Parte considerável da expansão destes postos administrativos fez-se em áreas de declive pronunciado, pois o centro ocupa a parte mais elevada do planalto. Tudo isto levou ao agravamento, não apenas das condições sociais, mas também ambientais; a cidade de Nampula é a capital provincial com os mais graves problemas de erosão.

A observação das fotografias aéreas de 1965 e de 1992 mostra que no posto administrativo da Muhala, por exemplo, ao longo da estrada que do centro vai até ao aeroporto e no enfiamento da pista de aterragem, em 1965 não havia população a residir e em 1992 a ocupação do solo era de 13 casas por hectare. Como de 1991 a 1997 este posto administrativo passou a ter mais cerca de 25 mil moradores, a densificação de ocupação do solo aumentou muito. Porque ela foi feita sem qualquer plano de ordenamento, a circulação e a instalação de infraestruturas são muito problemáticas e os problemas ambientais relacionados com a erosão e os lixos sólidos multiplicam-se, tornando as condições de vida dos seus moradores ainda mais precárias.

\section{O PESO DA POPULAÇÃO IMIGRANTE}

De acordo com os dados do INE, perto de metade (47\%) da população que actualmente reside na cidade de Nampula é imigrante. A atracção desta cidade exerce-se, fundamentalmente, sobre a população rural da província de Nampula, mas também dos distritos do norte da Zambézia, do sul de Cabo Delgado e do oriente do Niassa. Este aspecto reforça o papel central que a cidade desempenha em toda a região norte do país.

Tradicionalmente a migração rural-urbana para a cidade, como sucede nas restantes cidades do país e de Africa, é essencialmente masculina, o que se reflecte na razão de sexo de 114 homens por 100 mulheres em 1980 (CoNSELHO Coordenador Do ReCEnseamento, 1982). Contudo, a instabilidade que a guerra civil trouxe para as áreas rurais alterou muito a composição sexual e etária desta forma de mobilidade populacional, tornando as cidades um pouco mais femininas.

Durante o período aqui considerado (1980-97) a razão de sexo variou substancialmente: numa primeira fase (1980-91) o número de mulheres aumentou muito, passando a razão de sexo de 114 para 103 homens por 100 mulheres; na fase seguinte (1991-97) a predominância do sexo masculino voltou a acentuarse, mas sem alcançar os valores de 1980, passando para 109 homens por 100 mulheres. Parece ser evidente que durante a primeira fase, que correspondeu ao auge da guerra civil, terminada em 1992, veio para a cidade um maior número de mulheres que de homens, fenómeno observado em todas as áreas urbanas do 
país (ARAÚJo, 2003). Estas, para fugir à instabilidade rural, vieram juntar-se aos familiares do sexo masculino que já viviam na cidade. Com o final da guerra civil, a situação tende a voltar ao padrão migratório mais comum, em que as mulheres permanecem no campo enquanto os homens demandam a cidade em busca de trabalho que, a maior parte das vezes, não encontram no semi-paralisado sector formal da economia urbana.

Como sucede noutras cidades moçambicanas, é a «cidade de cimento», que, como já atrás se referiu, corresponde ao posto administrativo urbano Central, que apresenta um maior peso do sexo masculino. Em 1997, de acordo com os dados do recenseamento geral da população, a razão de sexo era, neste posto administrativo, de 120,4. Ao contrário, o posto administrativo urbano de Natikiri, que é o mais periférico, tem apenas 103,5 homens por 100 mulheres. $\mathrm{Na}$ realidade, a migração feminina fez-se mais em direcção aos bairros mais periféricos da cidade, onde as condições de vida são mais precárias.

\section{MIRAGEM DESFEITA}

A cidade sempre foi vista como o lugar a atingir para melhorar as condições de vida familiar. Esta ideia aprofunda-se mais em países que, como Moçambique, têm um desenvolvimento rural muito incipiente, e onde a agricultura praticada pela grande maioria das famílias depende, totalmente, das condições naturais. Por isso, as famílias rurais procuram que, pelo menos, um dos seus membros migre para a cidade para ter um emprego com remuneração certa, o que melhorará substancialmente o rendimento do agregado.

A cidade de Nampula sempre desempenhou esta função de atracção de população rural de todo o espaço provincial, assim como do norte da província da Zambézia, sul da de Cabo Delgado e oriente do Niassa. Também nesta função ela é considerada o centro de todo o norte moçambicano.

Contudo, durante as últimas décadas, apesar de as urbes moçambicanas continuarem a atrair muita população rural, arranjar nelas um emprego seguro e remunerado e melhorar as condições de vida da família, tornou-se uma miragem. Na cidade de Nampula esta situação é evidente pelo facto de ter recebido um volume muito grande de população rural fugida da guerra civil, como atrás foi referido, mas também porque durante esse período a cidade não criou novas infraestruturas e actividades económicas formais que levassem à criação de mais postos de trabalho. Esta situação foi agravada, ainda, pelo facto de muitas das actividades económicas comerciais e industriais existentes terem abandonado a cidade ou fechado por razões diversas.

Em 1995, da população em idade activa residente na cidade de Nampula, apenas 3,2\% tinham um emprego declarado ao Ministério do Trabalho e 1,8\% trabalhavam na função pública (Departamento de Estatística do Ministério do Trabalho, 1995; Direcção Provincial de Finanças de Nampula, 1995). Uma taxa de emprego oficialmente declarado de apenas $5 \%$ é extremamente baixa e 
geradora de graves problemas sociais e de gestão urbana de difícil controlo e de solução complexa. A cidade de Nampula em 1980 tinha um pouco mais de 30\% da sua população em idade activa oficialmente empregada (MINISTÉRIo DO TRABALHO, 1982), pelo que, tendo em conta os dados oficiais, num período de 15 anos a situação de emprego urbano tornou-se desastrosa. Esta quebra foi resultante da conjugação dos dois factores acima referidos (forte crescimento do fluxo migratório em direcção à cidade e paralisação e/ou degradação das infraestruturas económicas).

De entre os trabalhadores por conta de outrem, não incluindo os funcionários públicos, $50 \%$ estão empregados no comércio, fundamentalmente retalhista. De entre os que têm um emprego oficialmente declarado, cerca de $15 \%$ $(14,9 \%)$ exercem a sua actividade na agricultura; metade destes pratica, na cidade, uma agricultura de tipo familiar.

Estes dados mostram que, apesar do papel central que a cidade de Nampula tem para toda a região norte do país, não foram criadas as condições para o desenvolvimento de infra-estruturas e actividades que, de forma efectiva, criassem emprego para absorver a população lá residente e mais aquela que, continuamente, para ela se desloca na tentativa de melhorar as condições de vida. Nestas condições, a grande maioria da população em idade activa tem que buscar formas de sobrevivência, trabalhando sem qualquer tipo de vínculo contratual (exemplo claro dos empregados domésticos), ou procurando desenvolver actividades informais das mais diversas.

O informal urbano torna-se, nestas condições, a principal forma de actividade e de sobrevivência da população da cidade. No questionário de indicadores básicos de bem-estar, realizado pelo Instituto Nacional de Estatística em 2000, mais de $80 \%$ (85.7\%) da força de trabalho, a nível do país, era constituída por trabalhadores por conta própria e familiares não remunerados. Para a província de Nampula esse valor é superior a 90\% (92,9\%) (INE, 2001). Nas cidades, a maioria destes trabalhadores por conta própria são aqueles que se dedicam a actividades designadas por informais: vendedores de rua e de mercados, artesãos, transportadores, trabalhadores ocasionais, prestadores de serviços, etc. Apesar de não existirem dados exactos, estima-se que na cidade de Nampula, entre 65 e $70 \%$ da população em idade activa exerce a sua actividade no sector informal. Nestas condições, a cidade de Nampula, da mesma forma que outras urbes moçambicanas, tem na actividade não estruturada (informal) a sua principal fonte da economia familiar e urbana.

Uma parte dessa actividade não estruturada da cidade de Nampula faz-se na agricultura familiar e na venda dos seus excedentes nos mercados informais; são os «camponeses urbanos». Eles são constituídos por população que, vinda das áreas rurais, para sobreviver na cidade têm que continuar a usar a mesma actividade e as mesmas práticas que utilizavam nas suas áreas de origem. Por isso, o «camponês urbano» procura ter à volta da sua casa, na área urbana, uma pequena parcela com culturas diversificadas, como hortícolas, mandioca, milho e árvores de fruta. Quando isso não lhes é possível devido à intensificação da 
ocupação residencial, recorrem a outras parcelas mais afastadas da sua residência, dentro da área urbana ou no distrito rural, mas próximo da cidade. São exemplos desta situação as áreas de agricultura familiar e/ou cooperativa dos bairros Mutauanha, Marrere e Murrapaniua.

\section{UMA POPULAÇÃO ESSENCIALMENTE JOVEM}

Moçambique, como os restantes países de África, tem uma população muito jovem. O peso da população jovem acentua-se mais nas áreas urbanas, pois é nelas que a população jovem em idade de trabalhar procura melhores condições de vida, como se referiu acima.

A cidade de Nampula não escapa a esta regra, pois $43,5 \%$ da sua população tem menos de 15 anos, e apenas 1,2\% têm 65 ou mais anos (quadro IV). A população em idade escolar obrigatória (5-14 anos) representa 27,7\% dos residentes nesta urbe, o que dá uma ideia da pressão que existe sobre as infra-estruturas escolares, que apenas conseguem dar resposta a $70 \%$ das necessidades (Direcção Provincial de EducaÇão de Nampula, 2004).

Quadro IV - Estrutura etária da população da cidade de Nampula (Censo de 1997)

Table IV-Age structure of the population of the city of Nampula (1997 Census)

\begin{tabular}{lccc}
\hline \multirow{2}{*}{ Postos administrativos urbanos } & \multicolumn{3}{c}{ Grupos et rios (\%) } \\
\cline { 2 - 4 } & $\mathbf{<}$ & $\mathbf{5 - 1 4}$ & $\mathbf{6 5 +}$ \\
\hline Central & 11,2 & 25,2 & 1,2 \\
Muatala & 16,5 & 27,0 & 0,9 \\
Muhala & 15,5 & 27,8 & 1,4 \\
Namicopo & 16,4 & 26,3 & 1,5 \\
Napipine & 16,1 & 28,7 & 0,9 \\
Natikiri & 16,3 & 27,4 & 2,1 \\
Cidade de Nampula & 15,8 & 27,7 & 1,2 \\
\hline
\end{tabular}

A estrutura etária reflecte, igualmente, as diferenças existentes entre a "cidade de cimento» e o resto da cidade de Nampula, conforme se pode observar pelo quadro IV. Apenas aquela (posto administrativo urbano Central) tem uma população com menos de 15 anos que representa menos de $40 \%$ dos seus residentes $(36,4 \%)$, e a população em idade escolar é de apenas $25 \%$.

O posto administrativo urbano de Natikiri é o único onde a população idosa $(65+$ anos) tem um peso superior a $2 \%$. Este é, como já atrás foi referido, o mais periférico, onde o peso da população feminina é maior e que, ultimamente, tem perdido população a favor de outras áreas da cidade. 
Com esta estrutura etária, o nível de dependência, em particular nos bairros fora da "cidade de cimento", é muito elevado e as necessidades em infra-estruturas escolares e de saúde materno-infantil são grandes.

É esta população jovem que, durante o dia, conflui para a «cidade de cimento» (posto administrativo urbano Central) e percorre as suas ruas e avenidas oferecendo os seus préstimos para trabalhos ocasionais, vendendo aquilo que podem a quem passa ou juntando-se em grupos a jogarem qualquer coisa que os ajude a passar o tempo, etc. Isto dá ao centro da cidade uma aparência de grande congestionamento, assim como de alguma insegurança.

\section{BIBLIOGRAFIA}

Araújo, M. G. M. (2000) - Cidade de Maputo; espaços contrastantes: do urbano ao rural. Finisterra - Revista Portuguesa de Geografia, XXXIV(67-68): 175-190.

AraúJo, M. G. M. (2003) - Os espaços urbanos em Moçambique. GEOUSP-Espaço e Tempo, n. ${ }^{\circ} 14$ : 165-182.

Conselho Coordenador Do Recenseamento (1982) - I Recenseamento Geral da População 1980. Maputo, Direcção Nacional de Estatística, Comissão Nacional do Plano.

Conselho Executivo da Cidade de Nampula (1992) - Monografia da cidade de Nampula. Nampula, Edição do Conselho Executivo da Cidade de Nampula.

Departamento de Estatística do Ministério Do Trabalho (1995) - Estatísticas de emprego. Maputo, Ministério do Trabalho.

Direcção Nacional de Estatística (1992) - Enumeração populacional para o Inquérito Demográfico Nacional-1991. Maputo, Comissão Nacional do Plano.

Direcção Provincial de Educação de NAmpula (2004)-Estatísticas escolares 2003. Nampula, Direcção Provincial de Educação.

Direcção Provincial de Finanças DE NAmpula (1995)-Estatísticas provinciais de emprego. Nampula, Direcção Provincial de Finanças.

Instituto Nacional de Estatística (1999) - II Recenseamento Geral da População e Habitação 1997: Resultados Definitivos; Província de Nampula. Maputo, INE.

Instituto Nacional de Estatística (2001) - Questionário de Indicadores Básicos de Bem-estar; Relatório Final. Maputo, INE.

Ministério Do Trabalho (1982)-Relatório das estatísticas de emprego. Maputo. Ministério do Trabalho. 